\title{
Lower urinary tract autonomic dysfunction evaluation in spinal cord injury patients: an applied example
}

\author{
Hamza Mustafa Beano ${ }^{1}$ - Michael Kennelly ${ }^{1}$ \\ Received: 6 October 2017 / Revised: 14 October 2017 / Accepted: 14 October 2017 \\ (c) International Spinal Cord Society 2017
}

\section{Abstract Introduction}

The International Standards for the Neurological Classification of Spinal Cord Injury (ISNCSCI) is a measure for motorsensory dysfunction following spinal cord injury (SCI) but does not assess the autonomic nervous system dysfunction. The International Standards to document remaining Autonomic Dysfunction after Spinal Cord Injury (ISAFSCI) has been recommended to study autonomic dysfunction in such patients. We present a case presentation to demonstrate how to use the ISAFSCI and ISCoS urodynamics data set in persons with SCIs.

\section{Case presentation}

A 24-year-old caucasian male presents with T4 ASIA SCI. We followed the patient over the course of 18 months. We present his clinical picture at different stages and how to apply ISAFSCI and ISCoS urodynamic data set to this patient

\section{Discussion}

The ISAFSCI and ISCoS urodynamics data sets are important tools in the repertoire of the clinician assessing autonomic dysfunction in persons with SCIs. They allow efficient clinical assessment of patients and standard communication between clinical care providers.

\section{Introduction}

The International Standards for the Neurological Classification of Spinal Cord Injury (ISNCSCI) is an internationally recognized measure for the sensory-motor dysfunction following spinal cord injury (SCI). It has been found to be reliable [1] and valid [2]. Additionally, it has also been shown to increase the accuracy of formal neurological exam by practitioner [3]. However, the ISNCSI does not examine the autonomic dysfunction that can result from the SCI. Autonomic dysfunction assessment is important as it will have a significant influence on the patient's health and quality of life.

A joint Autonomic Standards Committee of the American Spinal Injury Association (ASIA) and the International Spinal Cord Society (ISCoS) supported developing a framework to assess Autonomic dysfunction following SCI.

Hamza Mustafa Beano

hamza.beano@carolinashealthcare.org

1 Department of Urology, Carolinas HealthCare System, Charlotte, NC 28207 USA
This was initially published in 2009 [4] and revised in 2012 as the International Standards to document remaining Autonomic Dysfunction after Spinal Cord Injury (ISAFSCI) [5]. It included standard assessment of general autonomic function, lower urinary function, bowel function, and sexual function. The committee also recommended adopting the ISCoS urodynamics data set [6] for urodynamic function assessment in the 2009 recommendations. Figs. 1 and 2 demonstrate the lower urinary function of ISAFSCI and ISCoS urodynamics data sets, respectively.

The ISAFSCI is yet to be a commonly used clinical tool. We aim to present a case as an example on how to use the lower urinary tract function subsection of the ISAFSCI and ISCoS urodynamics data sets to help guide practitioners in the clinical management of persons with SCIs.

\section{Case presentation}

A 24-year-old Caucasian male with no significant past medical history was involved in a motor vehicle accident in November of 2015. The patient was stabilized and his acute injuries managed. During his acute care hospital stay, he 


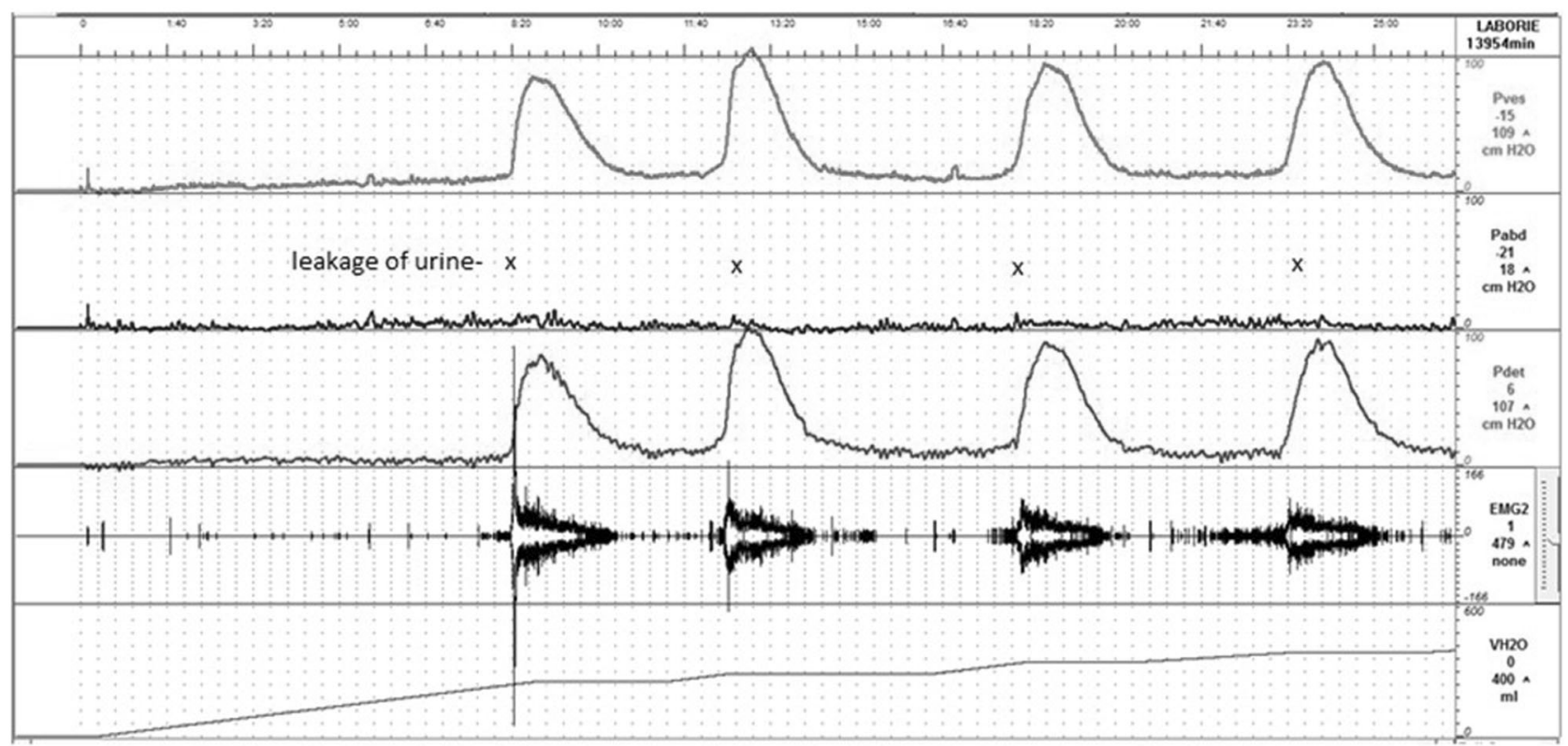

Fig. 1 Urodynamic findings of our case presentation

had a 16F Foley, which was exchanged weekly. This continued for about 1 month at which he was transitioned to clean intermittent catheterization (CIC). He presented in December to our rehabilitation hospital. His initial ISNCSI evaluation demonstrated that he sustained an ASIA SCI at the level of $\mathrm{T} 4$, which was consistent with his imaging findings. He denied any sensation in his bladder. He had continued CIC every $4 \mathrm{~h}$ without any urinary leakage. In filling the data set, we initially identified the level of injury. Since the injury was at T4 level, we placed the patient in the "supraconal" category. The patient did not have any bladder sensation and thus bladder awareness was recorded as 0 . Since the patient is only dry with CIC and would otherwise be incontinent, his ability to prevent leakage was recorded as 0 . Finally, his method of bladder emptying was CIC.

The patient returned in February 2016, 3 months after the injury. His bladder management remained CIC every $4 \mathrm{~h}$. $\mathrm{He}$ also reported mild pressure awareness in his bladder and leakage between CIC if he waits too long. His urinalysis and urine culture shows bacteriuria but he denies pelvic pain or foul urine. His ISAFSCI score was 1, 0, CIC.

The patient was lost to follow until November 2016, 12 months following injury, when he presented to clinic. He continued CIC every $4 \mathrm{~h}$ but reported urinary leakage despite $5 \mathrm{mg}$ oxybutynin three times per day. The oxybutynin was prescribed at an urgent care location. Patient also reported mild ill-defined abdominal pain as well as cloudy, foul-smelling urine. A urine sample was collected for culture and he was started on an empiric course of sulfamethoxazole $800 \mathrm{mg}$-trimethoprim $160 \mathrm{mg}$ BID. Urine culture resulted in growth of a pansensitive Escherichia coli species. Patient completed his antibiotic course and his symptoms resolved except the urinary leakage, which persisted. A renal ultrasound was done, which demonstrated normal size kidneys without masses or hydronephrosis. We asked the patient to return in December 2016 to perform a urodynamic test to assess his urinary leakage. The urodynamic study results are shown in Fig. 1. During the filling phase of the urodynamic study, the patient reported weak bladder sensation. We were able to fill the bladder with 400 cc of normal saline. The patient had four episodes of leakage and neurogenic detrusor overactivity. His detrusor pressure at first leakage was $42 \mathrm{cmH} 2 \mathrm{O}$ while his maximum detrusor pressure was $107 \mathrm{cmH} 2 \mathrm{O}$. Compliance was calculated and was found to be less $10 \mathrm{ml} / \mathrm{cmH} 2 \mathrm{O}$. Patient's calculated post-void residual during that visit was $87 \mathrm{ml}$ (not shown).

After finishing the urodynamic study, we increased the dose of his oxybutynin to $10 \mathrm{mg}$ TID. During his most recent follow-up in April 2017, patient reported he was doing well. He was still doing CIC $\mathrm{q} 4 \mathrm{~h}$ but the leakage stopped with the increased dose of oxybutynin. Patient would leak without the dose of oxybutynin. His ISAFSCI score was 1,0 , CIC.

\section{Discussion}

There has been significant increase in the survival of persons with SCIs [7], which encouraged the medical community to start thinking about long-term sequelae and quality-of-life issues beyond the traumatic injury and its 


\section{Asin}

Autonomic Standards Assessment Form

Patient Name:

\section{General Autonomic Function}

\begin{tabular}{|c|c|c|c|}
\hline System/0rgan & Findings & Abnormal conditions & $\begin{array}{l}\text { Check } \\
\text { mark }\end{array}$ \\
\hline \multirow{6}{*}{$\begin{array}{l}\text { Autonomic } \\
\text { control of the } \\
\text { heart }\end{array}$} & Normal & & \\
\hline & \multirow[t]{3}{*}{ Abnormal } & Bradycardia & \\
\hline & & Tachycardia & \\
\hline & & 0ther dysrhythmias & \\
\hline & Unknown & & \\
\hline & $\begin{array}{l}\text { Unable to } \\
\text { assess }\end{array}$ & & \\
\hline \multirow{6}{*}{$\begin{array}{l}\text { Autonomic } \\
\text { control of } \\
\text { blood } \\
\text { pressure }\end{array}$} & Normal & & \\
\hline & \multirow[t]{3}{*}{ Abnormal } & $\begin{array}{l}\text { Resting systolic blood pressure } \\
\text { below } 90 \mathrm{mmHg}\end{array}$ & \\
\hline & & Orthostatic hypotension & \\
\hline & & Autonomic dysreflexia & \\
\hline & Unknown & & \\
\hline & $\begin{array}{l}\text { Unable to } \\
\text { assess }\end{array}$ & & \\
\hline \multirow{6}{*}{$\begin{array}{l}\text { Autonomic } \\
\text { control of } \\
\text { sweating }\end{array}$} & Normal & & \\
\hline & \multirow[t]{3}{*}{ Abnormal } & Hyperhydrosis above lesion & \\
\hline & & Hyperhydrosis below lesion & \\
\hline & & Hypohydrosis below lesion & \\
\hline & Unknown & & \\
\hline & $\begin{array}{l}\text { Unable to } \\
\text { assess }\end{array}$ & & \\
\hline \multirow{5}{*}{$\begin{array}{l}\text { Temperature } \\
\text { regulations }\end{array}$} & Normal & & \\
\hline & \multirow[t]{2}{*}{ Abnormal } & Hyperthermia & \\
\hline & & Hypothermia & \\
\hline & Unknown & & \\
\hline & $\begin{array}{l}\text { Unable to } \\
\text { assess }\end{array}$ & & \\
\hline \multirow{6}{*}{$\begin{array}{l}\text { Autonomic and } \\
\text { Somatic Control } \\
\text { of Broncho- } \\
\text { pulmonary } \\
\text { System }\end{array}$} & Normal & & \\
\hline & \multirow[t]{3}{*}{ Abnormal } & $\begin{array}{l}\text { Unable to voluntarily breathe } \\
\text { requiring full ventilatory support }\end{array}$ & \\
\hline & & $\begin{array}{l}\text { Impaired voluntary breathing } \\
\text { requiring partial vent support }\end{array}$ & \\
\hline & & $\begin{array}{l}\text { Voluntary respiration impaired } \\
\text { does not require vent support }\end{array}$ & \\
\hline & Unknown & & \\
\hline & $\begin{array}{l}\text { Unable to } \\
\text { assess }\end{array}$ & & \\
\hline
\end{tabular}

Fig. 2 Complete ISAFSCI autonomic dysfunction data collection form

acute complications. Autonomic dysfunction is an important aspect of the long-term clinical care of persons with SCIs that must be well considered. The development of common standards for such injuries will improve injury classifications, communication between medical professionals and researchers, and may prove to have a prognostic value.

The ISNCSI is a valid, reliable measure of motor and sensory dysfunction that was initially developed by ASIA in 1982 and is currently in its seventh edition. Autonomic dysfunction still has not been adapted as part of the ISNCSI but ASIA and ISCoS developed the ISAFSCI in 2009 and revised it in 2012. Both groups recommend including the ISAFSCI in the assessment of persons with SCIs. We specifically presented a case to give an example on how correlate a clinical scenario with the lower urinary tract function of the ISAFSCI subset and ISCoS urodyamic basic
Autonomic Diagnosis: (Supraconal $\square$, Conal $\square$, Cauda Equina $\square$ )

\section{Lower Urinary Tract, Bowel and Sexual Function}

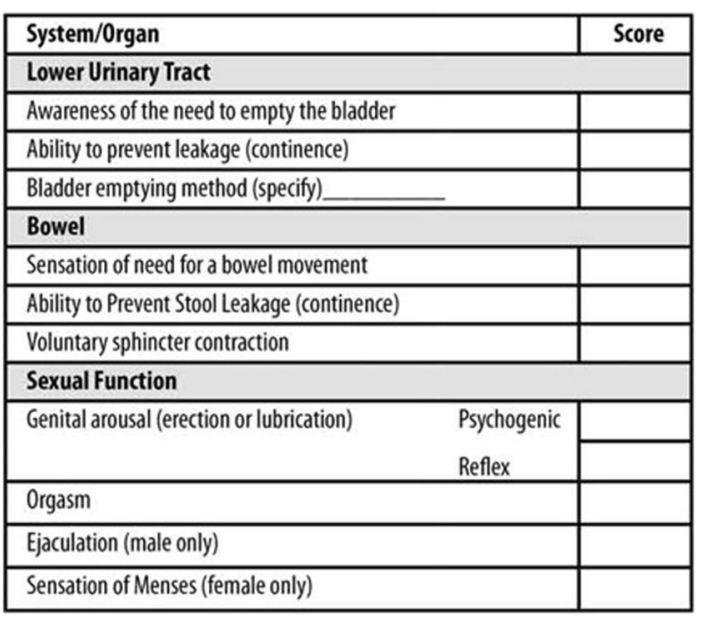

$2=$ Normal function, $1=$ Reduced or Altered Neurological Function $0=$ Complete loss of control, $\mathrm{NT}=$ Unable to assess due to preexisting or concomitant problems

Date of Injury Date of Assessment

This form may be freely copied and reproduced but not modified. This assessment should use the terminology found in the International SCI Data Sets (ASIA and ISCOS - http://www.iscos.org.uk)

Examiner

data set. The remainder of the ISAFSCI also includes general autonomic function, bowel function, and sexual function subheadings (Fig. 2); these are very important for the overall assessment of the patient but are beyond scope of our case presentation.

When completing the lower urinary tract function portion of the ISAFSCI, we start with classifying the patient according to the level of the injury as either supraconal, conal, or cauda equina. Supraconal lesions are above the sacral micturition center. They usually have intact sacral reflexes, overactive detrusor muscle, and detrusor sphincter dyssynergia. Conal lesions are lesions that damage the conus medullaris, which has the sacral reflex center. We further subdivide these lesions into types A and B. Type A is a conal lesion with damage to the detrusor nucleus, which controls the parasympathetic supply to the bladder. Such patients have an intact sacral reflex, they have 


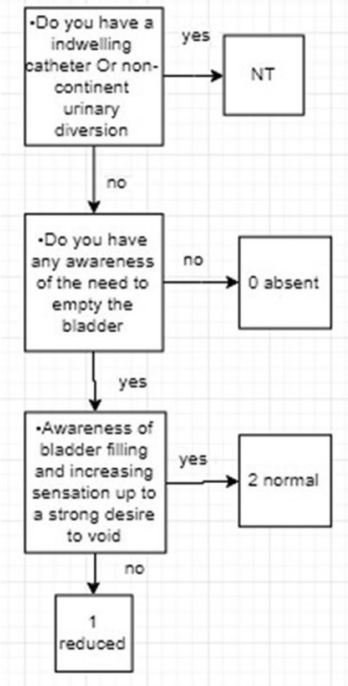

Fig. 3 Algorithm for answering "awareness of the need to empty the bladder" in the lower urinary tract subsection of ISAFSCI

hypocontractile/acontractile detrusor muscles, and also experience detrusor sphincter dyssynergia. Type B lesions are conal lesions with damage to the pudendal nucleus. Those patients will have absent sacral reflex, an incompetent sphincter, and an overactive detrusor function. The final lesion is rostral to the conus medullaris and involves the cauda equina or peripheral nerves. Such patients have absent sacral reflex, no sensation of their bladder, the detrusor is acontractile, and the sphincter is non-relaxing due to persistent sympathetic stimulation.

The ISAFSCI lower urinary tract function involves assessing three clinical aspects; the awareness of the need to empty the bladder; ability to prevent leakage; and the method of bladder emptying. The first two aspects are scored on a scale from 0 to 2 and NT, 2 representing normal function, 1 representing reduced function, and 0 representing absent function. NT is unable to assess due to preexisting or concomitant problem. The third clinical aspect depends on the method of bladder emptying as foley catheter or intermittent catheterization. We have included 2 algorithms to assist with answering those questions (Figs. 3 and 4). It should be noted that the first and second questions must be answered considering the intrinsic, current condition of the patient without the added benefit of any medical intervention. Thus, our patient had a leakage score of zero despite being dry on CIC and oxybutynin. The reason is that we must consider his intrinsic neurological status without the benefit of our medical intervention. This is a confusing aspect of ISAFSCI since the standards do not clearly state whether the assessment should be performed while the patient is on or off medications/interventions. However, the standards clearly state that score 2 should be used when there is no change in neurologic control with respect to a

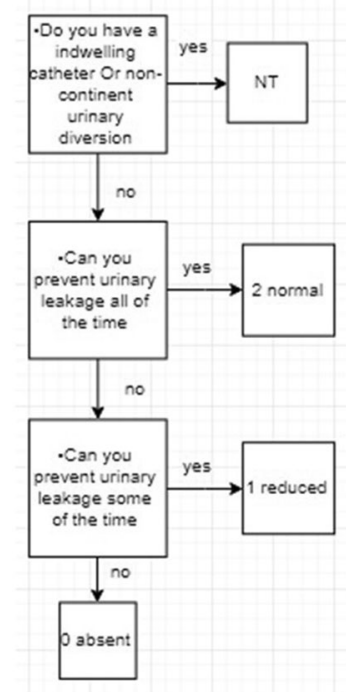

Fig. 4 Algorithm for answering "ability to prevent leakage" in the lower urinary tract subsection of ISAFSCI

specific function. A person with SCI with residual neurological deficit whose symptoms are controlled with medical therapy could not score 2 on ISAFSCI. It would be reasonable to use ISCoS data sets in situations where communicating effectiveness of medical interventions on a patient's clinical picture.

The ISCoS basic data set assess eight urodynamic aspects [6]. The first is bladder sensation during filling cystometry, which can be normal, increased, reduced, absent, or nonspecific. Normal bladder sensation can be judged by three defined points noted during filling cystometry and evaluated in relation to the bladder volume at that moment and in relation to the patient's symptoms. Increased bladder sensation is defined as an early first sensation of bladder filling (or an early desire to void) and/or an early strong desire to void, which occurs at low bladder volume. Reduced bladder sensation is defined as diminished sensation throughout bladder filling. Absent bladder sensation means that the individual has no bladder sensation. Nonspecific bladder sensations are atypical sensations experienced during filling, which the patient does not attribute to his bladder, for example, abdominal fullness or vegetative symptoms.

Detrusor function can be normal, underactive, neurogenic overactive, or acontractile. Normal detrusor function allows bladder filling with little or no change in pressure. No involuntary phasic contractions occur despite provocation. Detrusor overactivity is a urodynamic observation characterized by involuntary detrusor contractions during the filling phase, which may be spontaneous or provoked. Detrusor underactivity is defined as a contraction of reduced strength and/or duration, resulting in prolonged bladder emptying and/or a failure to achieve complete bladder 
emptying within a normal time span. Acontractile detrusor is one that cannot be demonstrated to contract during urodynamic studies.

Urethral function during voiding can be normal, may show detrusor sphincter dyssynergia, or show non-relaxing urethral sphincter obstruction. Normal urethral function is defined as urethra that opens and is continuously relaxed to allow the bladder to be emptied at a normal pressure. Detrusor sphincter dyssynergia is defined as a detrusor contraction concurrent with an involuntary contraction of the urethral and/or periurethral striated muscle. Occasionally, flow may be prevented altogether. Non-relaxing urethral sphincter obstruction usually occurs in individuals with a neurological lesion and is characterized by a nonrelaxing, obstructing urethra resulting in reduced urine flow.

There are also five parameters to be included in the data set, which includes compliance of $<10 \mathrm{ml} / \mathrm{cmH} 2 \mathrm{O}$, detrusor leak point pressure in $\mathrm{cmH}_{2} \mathrm{O}$, maximum detrusor pressure in $\mathrm{cmH}_{2} \mathrm{O}$, cystometric bladder capacity in $\mathrm{ml}$, and postvoid residual volume in ml. Compliance is ideally calculated as change in bladder volume divided by change in detrusor pressure. However, since a numerical value is not required, practitioners often tend to estimate the compliance as less than or greater than $10 \mathrm{ml} / \mathrm{cmH}_{2} \mathrm{O}$ from the shape of the bladder filling curve. Detrusor leak point pressure is lowest detrusor pressure at which urine leakage occurs in the absence of either a detrusor contraction or increased abdominal pressure. Maximum detrusor pressure is peak detrusor pressure achieved by the detrusor muscles during filling. Cystometric bladder capacity is the maximum volume of fluid infused into the bladder during the filling phase. Finally, post-void residual is the amount of urine remaining inside the bladder after the patient has voided.

It is important to note that the updated version of ISAFSCI eliminated the urodynamic component from the form since "a majority of individuals will not have this assessment in the acute and sub-acute period of rehabilitation". Thus, "most of the time this component of the form will be left empty". However, ISAFSCI still "strongly recommended that urodynamics be routinely performed following SCI" [5]. We believe that the urodynamic data set provides an informative, applicable way of communicating such data.

The ISCoS has published more extensive data sets that present detailed data collection templates on multiple clinical aspects in SCI involving specific aspects such as skin thermoregulation, sexual function, upper urinary tract imaging, and more. The goals for the data sets were to disseminate standards for the collection of data from participants enrolled in studies of neurological diseases, create easily accessible tools for investigators to collect study data, and encourage focused and simplified data collection to reduce the burden on investigators and practice-based clinicians [8]. Although the data sets provide a wealth of information and may be used as standardized ways of data collection for clinical care and communication, we feel that they are quite extensive and not applicable to the pace and practice models of some clinical situations. We believe that the ISAFSCI an effective, practical method of defining the baseline of the autonomic neurological status of persons with SCIs and that ISCoS data sets may be more appropriate to monitor changes with clinical interventions in addition to the goals stated above.

Management of chronic medical and quality-of-life issues is an important part of the holistic care of persons with SCIs. Autonomic functions, especially lower urinary tract, can result in significant morbidity and detriment to the quality of life of persons with SCIs if not properly addressed. A very important step is to find a common, practical framework in describing and assessing such dysfunction. We believe that the ISAFSCI is a very initial step in achieving this goal. We hope that with wider application, it will show prognostic value as well.

\section{Compliance with ethical standards}

Conflict of interest M.K.: study trial/Investigator: Allergan, Amphora, Boston Scientific, Cook Myosite, Ipsen, and Taris; Consultant: Allergan, Astellas, Boston Scientific, and Coloplast. The remaining author declare that they have no competing interests.

\section{References}

1. Marino RJ, Jones L, Kirshblum S, Tal J, Dasgupta A. Reliability and repeatability of the motor and sensory examination of the international standards for neurological classification of spinal cord injury. J Spinal Cord Med 2008;31:166-70.

2. Graves DE, Frankiewicz RG, Donovan WH. Construct validity and dimensional structure of the ASIA motor scale. J Spinal Cord Med 2006;29:39-45.

3. Schuld C, Wiese J, Franz S, Putz C, Stierle I, Smoor I, et al. Effect of formal training in scaling, scoring and classification of the International Standards for Neurological Classification of Spinal Cord Injury. Spinal Cord 2013;51:282-8.

4. Alexander MS, Biering-Sorensen F, Bodner D, Brackett NL, Cardenas $\mathrm{D}$, Charlifue $\mathrm{S}$, et al. International standards to document remaining autonomic function after spinal cord injury. Spinal Cord 2009;47:36-43.

5. Kirshblum SC, Burns SP, Biering-Sorensen F, Donovan W, Graves $\mathrm{DE}$, Jha $\mathrm{A}$, et al. International standards for neurological classification of spinal cord injury (revised 2011). J Spinal Cord Med 2011;34:535-46.

6. Biering-Sorensen F, Craggs M, Kennelly M, Schick E, Wyndaele JJ. International urodynamic basic spinal cord injury data set. Spinal Cord 2008;46:513-6.

7. van den Berg ME, Castellote JM, de Pedro-Cuesta J, MahilloFernandez I. Survival after spinal cord injury: a systematic review. J Neurotrauma 2010;27:1517-28.

8. Biering-Sorensen F, Alai S, Anderson K, Charlifue S, Chen Y, DeVivo $M$, et al. Common data elements for spinal cord injury clinical research: a National Institute for Neurological Disorders and Stroke project. Spinal Cord 2015;53:265-77. 